\title{
FIRST AID TO CULTURAL HERITAGE. TRAINING INITIATIVES ON RAPID DOCUMENTATION
}

\author{
A. Almagro Vidal ${ }^{\mathrm{a}}$, A. Tandon ${ }^{\mathrm{b},}$, R.. Eppich ${ }^{\mathrm{c}}$ \\ ${ }^{a}$ Fundación Montemadrid, Madrid, Spain. ana.almagro@gmail.com \\ ${ }^{\mathrm{b}}$ International Centre for the Study of the Restoration and Preservation of Cultural Property, Rome. at@iccrom.org \\ c Universidad Politécnica de Madrid (UPM), Escuela Técnica Superior de Arquitectura, Madrid, Spain. randeppich@gmail.com
}

\section{SESSION G1 - CULTURAL HERITAGE AS COLLATERAL DAMAGE IN CONFLICTS}

KEY WORDS: Emergency, conflict, natural disaster, first aid measures, cultural heritage, training, rapid documentation, $3 \times 3$ rules

\begin{abstract}
:
Recent dramatic events have brought to the forefront the debate on how to protect, safeguard and document Cultural Heritage in conflict areas. Heritage places have become battlefields, sources of illicit trafficking and even deliberate targets of destruction because of the politicisation to further conflict ideologies as well as misinterpretation of the values they represent. Is it possible to protect Cultural Heritage under such circumstances? If yes, when is the right time to intervene and who can help in this task? How can documentation and training assist?

The International Course on First Aid to Cultural Heritage in Times of Crisis promoted by ICCROM (The International Centre for the Study of the Preservation and Restoration of Cultural Property) in collaboration with various partners focuses specifically on ways to help in such difficult and stressful situations. This paper explores the methodological approach and highlights the special circumstances that surround rapid documentation and preliminary condition assessment in conflict areas, and in cases of complex emergencies such as an earthquake striking a conflict area. The paper identifies international actors that might play a special and crucial role in the first steps of such a situation and recognizes the need for training activities to strengthen capacities for disaster response to cultural heritage at national and regional levels.
\end{abstract}

\section{INTRODUCTION}

The Hague Convention, which is still the only global legislation that establishes international standards for the protection of cultural property during armed conflict, celebrated its 60th anniversary last year. At same time, we have witnessed an unprecedented rise in the intentional destruction of cultural heritage due to armed conflicts. It appears to be a new form of terrorism that is being promoted through planned marketing campaigns which are spread through new digital and social media channels to magnify their reach, impact and shock.

\subsection{Background and Need}

"Culture is a basic need"; culture gives hope to impacted communities and restores human dignity, and contributes to continuity and a sense of identity - it is an integral part of human aid" Prince Claus (Van der Plas and Mendez, 2006).

People suffer greatly during conflicts and natural disasters. The loss of life, dissolution of families and the rifts in society are atrocious. During such times it is the human needs that prevail and must be addressed - first aid, security, food and shelter. With this in mind there must also be a view to the future - to begin mending the connecting fabric of society, provide hope and a connection to the past as well as address economic possibilities through preserving and restoring cultural sites and institutions. Throughout the world there are a large number of Cultural Heritage places that have been damaged through armed conflicts, looting and vandalism, including, Syria, Iraq, Afghanistan, Mali, Bosnia \& Herzegovina, Yemen, etc. etc. The list is very long indeed.
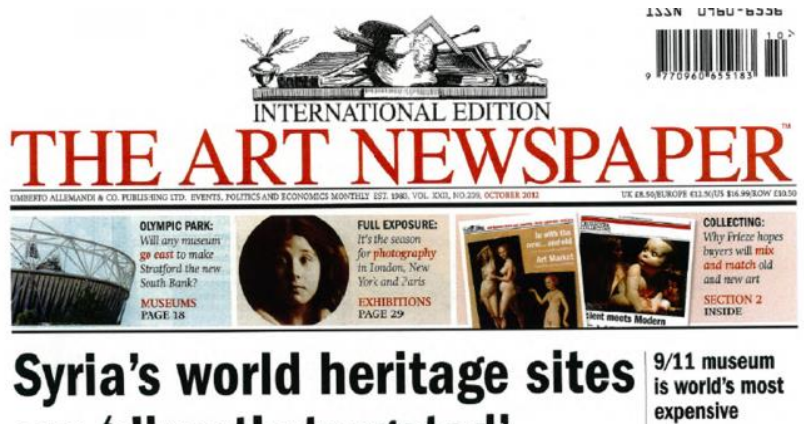
are 'directly targeted'

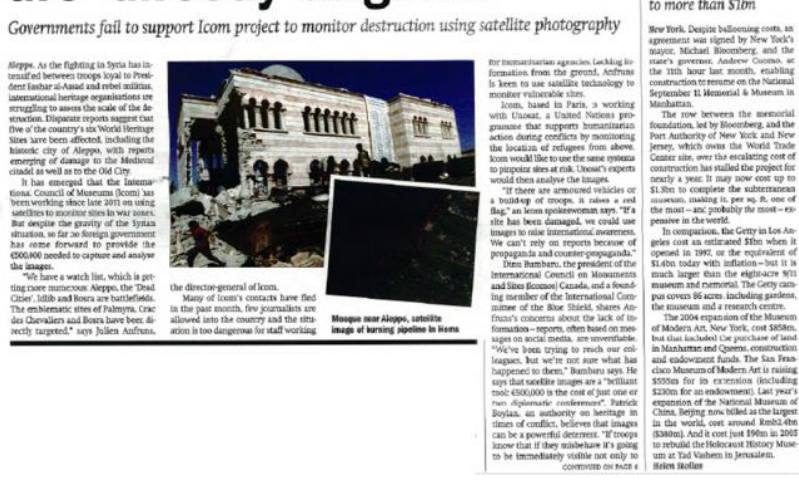

Figure 1. Documentation for cultural heritage sites at risk also includes collecting secondary sources of information from newspapers, social media and other digital content. 
Culture has long been recognized as an essential aspect for recovery having a positive force both for social reconstruction and cohesion and for eventual reconciliation. In many situations there is strong evidence from those who have suffered through conflicts and disasters to restore sites and institutions and to reestablish the familiar (Stanley-Price, 2007). The protection and recovery of Cultural Heritage plays a crucial role in rebuilding societies and in overcoming the sense of loss and displacement (Tandon, 2010).

While the physical, societal and economic impacts of conflicts and natural hazard events on Cultural Heritage appear to be quite similar but, in actual effect they differ. Cultural emergencies induced by armed conflicts, especially internal ones, require a different approach and response. The response is made more difficult when emergencies such as earthquakes overlap or cross-cut armed conflicts causing more complex emergencies and involve multifaceted and multi-causal crisis (Tandon, 2015).

Present day conflicts frequently stem from identity politics and target communities through their places of worship, symbols, pride and identity - anything that carries special significance. In many cases the goal of the attacks is clearly any tangible element with some value to the community, turning Cultural Heritage into a specific target (Fig. 1). This modus operandi impacts religious groups, minorities and even entire nations including their intangible heritage - celebrations, rituals, traditions, activities - all deeply linked to places, sites and the territory. These circumstances make relief and the recovery processes even more complicated and delicate.

Furthermore, there are links between poorly managed cultural heritage and increased vulnerability to identity based conflicts which are only now beginning to be understood. In fact, this lends strength to the argument that if culture is part of the perceived problem, it can also be part of the solution.

\subsection{Response}

In response to the need to address Cultural Heritage after natural disasters and conflicts ICCROM (The International Centre for the Study of the Preservation and Restoration of Cultural Property) created in 2011 the International Courses on First Aid to Cultural Heritage in Times of Crisis (FAC). This series of courses, held in Rome and Amsterdam, seeks to answer the question:

Is it possible to protect cultural heritage during complex emergencies in order to promote recovery and reconciliation?

The training is based on the inputs from other mainstream emergency actors such as military and humanitarian agencies. It aims to prepare national teams of cultural first-aiders ${ }^{1}$ who must

\footnotetext{
${ }^{1}$ According to ICCROM's First Aid training, a cultural firstaider is a person who has the necessary knowledge and skills to document as well as protect cultural heritage during a complex emergency. She/he is proactive yet sensitive to human needs, respectful of the local context, capable of building trust and understanding amongst people who have different views, able to develop and implement first aid operations for protecting Cultural Heritage in coordination with other relief agencies, able to constitute and manage teams, and capable of assessing and mitigating future risks in order to ensure early recovery.
}

have the ability to assess risks to cultural heritage and reduce the impact of such events. The topics covered in the course try to enhance participants' skills for assessing and responding during complex emergency situations (Fig. 2). The training is multidisciplinary as well as interactive. Learning activities range from simulated emergency events to role-playing and group discussions, which help develop leadership skills. The training encourages participants to play a key role in developing initiatives for disaster risk management of Cultural Heritage in their respective countries by providing limited number of seed grants (ICCROM, 2015). Key topics in the course include:

- Conflict / emergency context analysis and mapping of actors

- International legislation for cultural heritage protection

- Ethics and principles of conservation in crisis situations

- Emergency documentation for movable and immovable heritage

- First-aid to historic structures and cultural collections

- Mediation and negotiation skills, teamwork

- Crisis management and personal security

- Culture and international humanitarian aid

- Post-crisis recovery

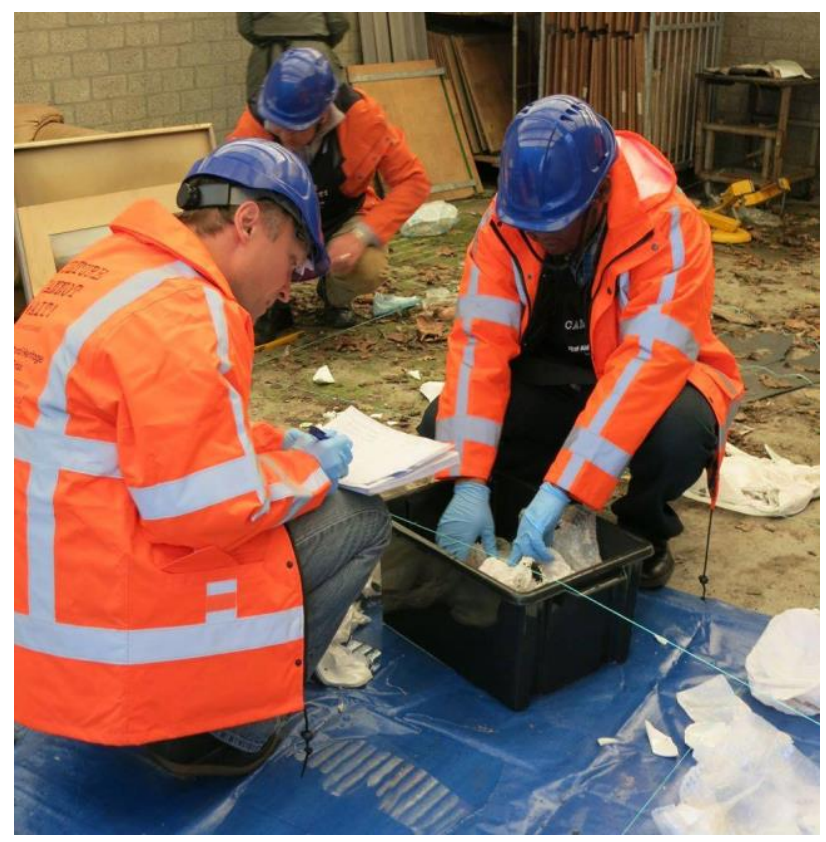

Figure 2. Rapid documentation and inventory exercise during an emergency simulation at an ICCROM First Aid course (ICCROM, 2015)

\subsection{Role of Documentation for Monuments and sites}

One important element in these courses is emergency documentation; both for immovable heritage as well as movable heritage. The scope of this paper is the analysis of existing documentation protocols and their adaptation to situations of conflict for both small and large scales. It will describe the development of a strategy and methodology for monuments and sites that has been developed during the course. Extensive feedback was provided by experts and participants during the courses and after actual crisis situations. 
During the emergency phase during or immediately following conflicts cultural heritage must be documented using different methods, techniques and processes than under usual circumstances. The political, security and safety situations and overall context must be known, communicated and acted upon in a well-thought out process. The prior existing baseline conditions, level of significance, state of conservation, damages and location are just some of the few elements of documentation that must be known on a large scale. Primary and secondary sources must be coordinated, verified and shared with the decision makers, actors and international experts. In many cases secondary sources are more available but also more difficult to verify. In addition, skills (or lack thereof) of those available onthe-ground where they can make a difference is an additional form of documentation. All of this assists in prioritizing and clearly focusing action where and when it is needed for the best possible response. Better information leads to better decisions and this is never more important than in first aid circumstances.

\section{METHODOLOGY}

\subsection{Understanding, Research \& Investigation}

Developing the methodology for documentation during times of crisis and for teaching in the First Aid courses was an important first step. Understanding then adapting standard documentation methods, tools and approaches was necessary as well as gaining an understanding of what actually happens during and immediately after a crisis. This was done through several steps including first-hand experiences in several crisis and post-crisis situations, interviews with course participants, discussions with experts and instructors as well as extensive research. This body of knowledge was collected together, summarized and adapted into training materials and a bibliography.

\subsection{Trial during the courses}

As the training comes as response to newer and more complex threats to Cultural Heritage, all the knowledge and approach methodology for documentation had to be tested. This testing was conducted during mock disaster sessions, and regional applications of ICCROM FAC courses ${ }^{2}$. Each time the methodology, response, materials and tools were evaluated; revised and improved.

In terms of documentation, an important factor in this methodology was the flexibility to accommodate and adapt for constantly changing technology. Over the past decades capture technology has changed greatly - camera sensors, software, mobile networks, techniques and measuring devices. These courses proved to be a training ground for the adaptation of the methodology for changing technological conditions. In this regard the critical issues were flexibility, transferability, availability given limited time to train for complex situations and adaptability for people from completely diverse backgrounds coming from different places and facing every possible kind of crisis.

\footnotetext{
2 This is the case, among others, of the training initiative "ICOMOS-ICCROM e-learning courses for Syrian cultural heritage professionals" for the Protection of Syria's Cultural Heritage in Times of Armed Conflict promoted in 2013: http://www.icomos.org/en/home/178-englishcategories/news/569-protection-of-syria-s-cultural-heritage-intimes-of-armed-conflict-icomos-iccrom-e-learning-course-forsyrian-cultural-heritage-professionals
}

\subsection{Evaluation feedback during actual crisis}

Many of the former participants and instructors have since responded to crisis situations. Their feedback has been invaluable for improving the methodology (ICCROM, 2012). This methodology is constantly being adapted and adjusted for actual situations. In addition, research is underway and secondary sources such as satellite imagery and social media are constantly being appraised. Given the special circumstances of a crisis this was more important than ever.

\section{SPECIAL CIRCUMSTANCES OF RAPID DOCUMENTATION}

Documentation for immovable cultural heritage is simultaneously diverse and broad yet a very specialized field. The documentation needs of cultural heritage sites are unique and vary from locating small archaeological details in earthen strata to structural calculations of masonry domes to inventories on a territorial basis. The tools used by those in this field are equally diverse and can include complex instruments such as 3D laser scanners, UAV or drones, satellite imagery and infrared imaging cameras or as simple as mobile telephone cameras, paper and pencils. Crisis situations make this already complicated field even more so:

- Cultural heritage is often disregarded by first responders understandably more concerned with humanitarian needs

- Cultural heritage is frequently a specific target during armed conflicts given its importance to communities

- Documentation must be done rapidly as often the damage is both extensive and intensive and on-going. After conflicts officials are often eager to move forward with recovery and remove dangerous structures.

- Crowdmapping initiatives, if well-coordinated and managed, can provide useful and onsite information in real time. But must have dedicated management over time.

- Primary sources of information (on site investigations) are often unavailable as places are dangerous thus secondary sources may even be more valuable and easier to obtain.

- Standards, accuracy and established methods usual for "proper" documentation are often compromised

Special concern is taken regarding this last point, as there is very limited time in which train responders in such a complex process. Many times it is impossible to train on site or directly with the people who will conduct the documentation. Often tolerance and acceptance is necessary as untrained responders are only trying to do their best with very limited resources; even risking their lives. This context forces the methodology for documenting cultural heritage for first aid to maintain a realistic, basic and hyper-rapid approach with the main objectives of consistency and systematic documentation mainly based on photographic coverage.

This basic documentation process, for professionals dedicated to the field becomes a serious challenge, as documentation relies many times on non-expert individuals who will have the unique opportunity to record the only (or last) evidence of significant artefacts, buildings or sites that might be further damaged or destroyed. These first aid documenters are local people, military forces and volunteers. This is the main reason why the methodology stresses the need to capture, as much as possible, good photographs. This is of key importance and centres the scope of the simulation sessions organized during the course. 


\section{TRAINING ACTIVITIES TO STRENGTHEN CAPACITIES IN DOCUMENTATION}

\subsection{Understanding Documentation in crisis}

In order to address the special situation with documentation and immovable cultural heritage in crisis the course module from the FAC course is presented here. This information has been taken from numerous courses - ICCROM ARIS courses (Architectural Records, Inventories and Information Systems for Conservation), CIPA courses and other university courses held at the University of Granada, KU Leuven and University of Pennsylvania (Eppich and Almagro Vidal, 2013) but it has been adapted for the special situations surrounding sites in conflict areas. Throughout the courses it was emphasized that the record the participants were making could be the last evidence of Cultural Heritage (Fig. 3). It was stressed that this was of utmost importance and therefore certain principles and guiding principles should be followed.

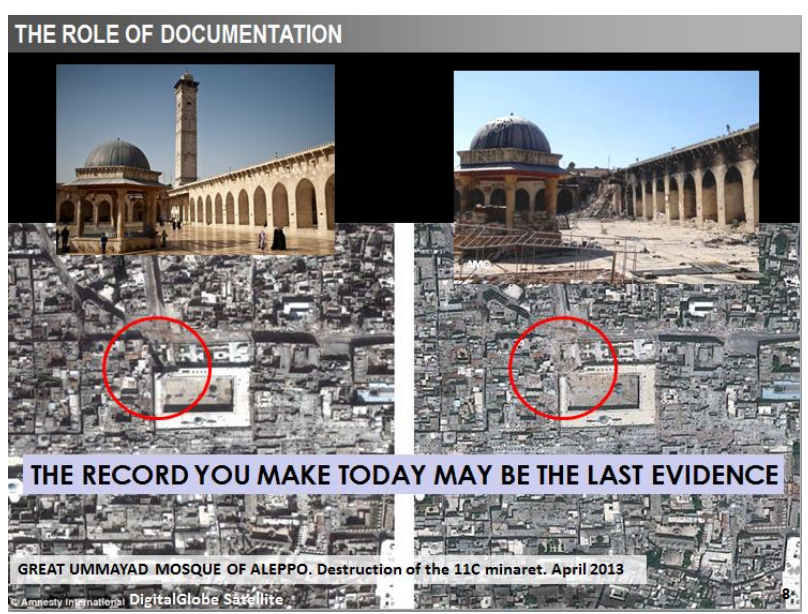

Figure 3. Image before and after recent destruction in Aleppo, Syria with satellite imagery below

\subsection{Learning Objectives}

Based on the main goal already highlighted for the documentation module, the learning objectives for this part of the course included:

- General overall of the principles for rapid documentation in times of conflict. This included a comparison of principles of documentation in a normal situation and principles for rapid documentation. It emphasized that the documentation must be fast, easy, methodical and strategically planned to ensure a complete covering of the site or building (ICOMOS, 1996).

- Methodology useful for rapid documentation that can later be extended. This included an introduction to the $3 \times 3$ rules developed by CIPA (Waldhäusl and Ogleby, 1994). Usually there is little time to go through all nine rules that this methodology establishes but an impact is created specifically on the importance of photography and the way photos must be captured in combination with other tools.

- Extending the use of existing tools - to understand and get more from the tools that are readily available. In a crisis situation it is not a matter of available technology or cutting edge tools, but methodology and strategy, so the aim is to make this point clear to participants.

- Exposure to other examples of rapid documentation. To learn how basic data collected together with strategic photo capture is enough to provide a basic data set for preliminary assessment and even first processing for emergency intervention. Other crisis situations were explained and how other disciplines document their topic.

- Resources for participants to learn more on their own including a list of readings, websites, initiatives and newspaper articles.

- Tools which are low cost or free for all participants. This included software and hardware. Often developing countries are hit harder and more advanced tools are not available. Participants installed the software on their own computers, smartphones and tablets. Even if time was very limited, some individual sessions were held to focus on which tools were appropriate to each participant's home country.

- Contacts database of individual experts, institutions and intergovernmental bodies such as ICCROM, UNESCO and ICOMOS both regionally and internationally should additional assistance be necessary. This took the form of a simple Excel spread sheet that included names, expertise descriptions, telephone numbers, cell phone numbers and multiple email addresses.

- Standards in the form of International Community, Charters and Initiatives. This may seem unnecessary in an emergency but often it was discovered that this was powerful support in the field when working at significant sites.

\subsection{Guiding Principles for Documentation}

Documentation must be fast, efficient, low-cost, easy-to-use and to train others, easy to share, manage and importantly the capability to process and extract further information later. It is a constant balancing act between doing what is necessary at the moment and longer term needs, therefore the guiding principles (ICOMOS, 1996) were discussed during the training and each participant was encouraged to develop their own principles based upon their country's needs and problems. A summary of these guiding principles are outlined here:

- Reasons - this was required as an explanation for why documentation is required. This is even more important in an emergency situation when there is a humanitarian crisis.

- Responsibilities - each person on a team was critical and efforts could not be duplicated or, worse, areas or sites missed. So outlining clear responsibilities was a key guiding principle. This answered the question of who was responsible with a clear reporting structure.

- Planning - was an essential principle in order to properly address the shortages caused during an emergency - time, money and skills. These had to be properly addressed and assisted in answering the when and where questions.

- Content of the record - this addresses the what question and takes into account that it is an emergency and what is primarily needed (basic data requirements)

- Management, dissemination and sharing of records - when information sharing is key for a rapid and effective response

- Quality of information - Providing sufficient good information to lead to good first aid conservation decisions 
- Rapid response - Permitting a quick understanding of the site context and its problems

- Dissemination - the use, manage and sharing of the information collected as a tool to tackle first aid conservation strategies

\subsection{Basic Data Requirements}

Basic Data Requirements were a key aspect when working with the participants. There were three basic levels of recording mentioned (Letellier, 2007). This included level A - basic recording, level $\mathrm{B}$ - more advanced recording, and $\mathrm{C}$ - detailed and accurate recording (Fig. 4).

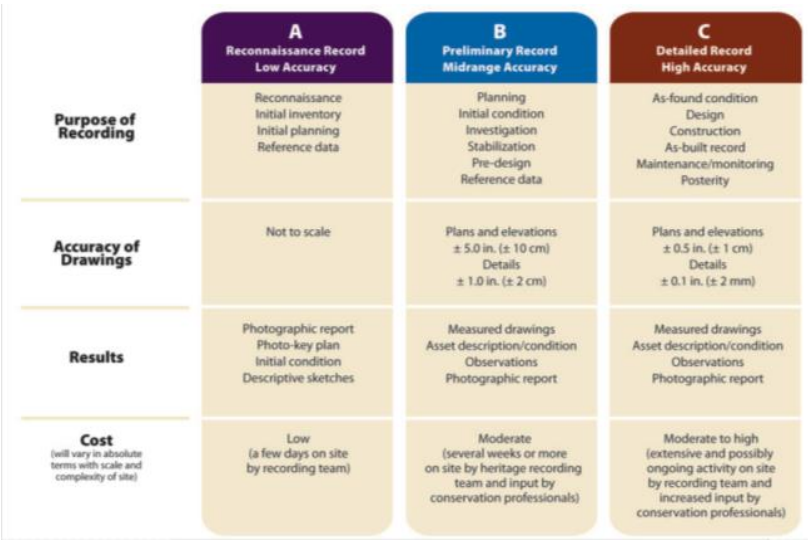

Figure 4. Levels of documentation A-rapid, B-detailed and Chighly accurate. During the courses it was stressed that information from one must inform the next (Letellier, 2007)

It was discussed how these levels are interrelated and that information collected in level A could eventually be useful in level $\mathrm{C}$. This was stressed as many times after crisis there is a requirement to follow up and document many times a building or series of them, to monitor their condition as monuments are continually being damaged or it may be several years before interventions. While exercises were only conducted for recording level A there were examples given of levels B and C.

\subsection{A 3 step methodology}

Basic Data Requirements were discussed in a three step methodology that aimed at helping to establish an approach strategy and provide a framework to proceed once a crisis has started.

4.5.1 Step 1: Prepare before going into the field. This step included:

- $\quad$ Preparation of a documentation kit (Fig. 5)

- Collection of information prior from the archive, internet, newspapers, secondary sources, etc.

- Satellite imagery and other secondary data sources including interviews from recent first-hand accounts

- Collection of any other source of information that could be useful, especially social media

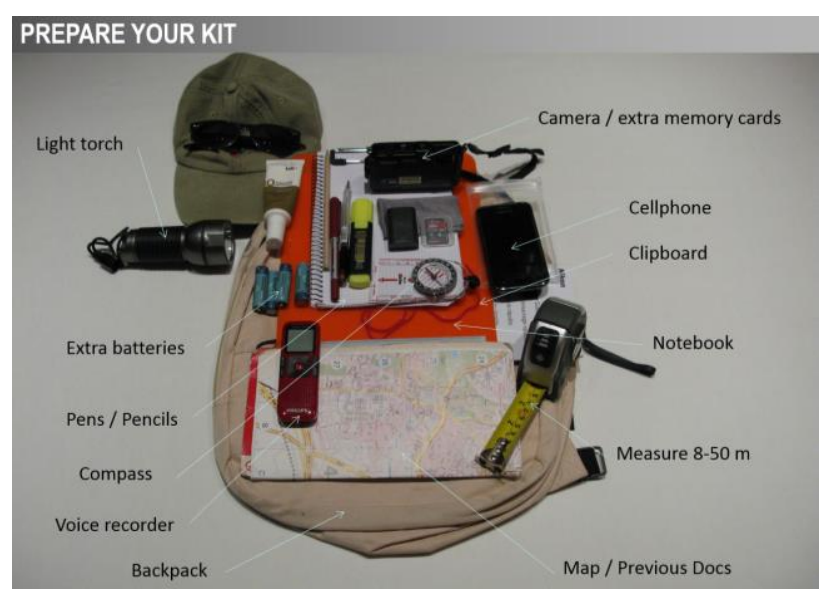

Figure 5. Basic kit for emergency documentation. Such kits were constructed during the courses. An important aspect of this

was to have backup documentation tools, techniques and systems (Eppich and Almagro Vidal, 2013).

4.5.2 Step 2: Understand and plan upon arrival. Once the situation permits on the ground documentation some key rules were established to keep the process consistent and systematic:

- Assessment for the safety for personnel. It was stressed that if personal safety was at any way at risk the documentation mission must be cancelled. It was stressed that there should always be a backup site.

- Reconnaissance to understand the site, surroundings, context and conditions. An exploration to gain information rapidly and plan activities.

- Observation of the light and its effect on the subject and time of day.

- Planning to create a schedule and establish a strategy to collect data consistently and systematically, with no gaps (Fig. 6). Special attention must be given if the work is carried out in teams: who does what, where and when.

- Collecting information from local people, when did the damage occur? How often? What was the monument like before?

- Prioritization and outlining realistic expectations in order to accomplish the minimum and not forget important items.

- Assessment if additional help or additional expertise is required, especially concerning stabilization of structures and immediate first aid actions.

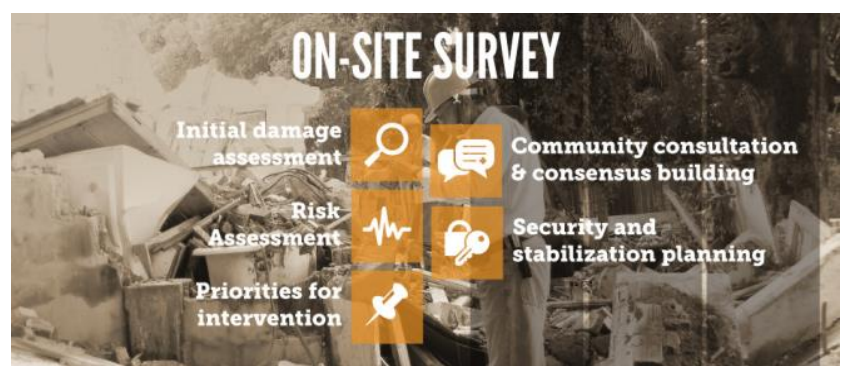

Figure 6. On-site survey was stressed at other points in the course (ICCROM, 2015) 
4.5.3 Step 3: Capture using the $3 \times 3$ rules (Fig. 7). As mentioned earlier the background of the potential team that will record the site or building in danger or damaged might not be technical enough to understand certain concepts and terms that are common in the specialised field of cultural heritage documentation (camera components, parallax, photogrammetry, calibration, bundle adjustment, etc.). This is an added difficulty that challenges the documentation process and its results.

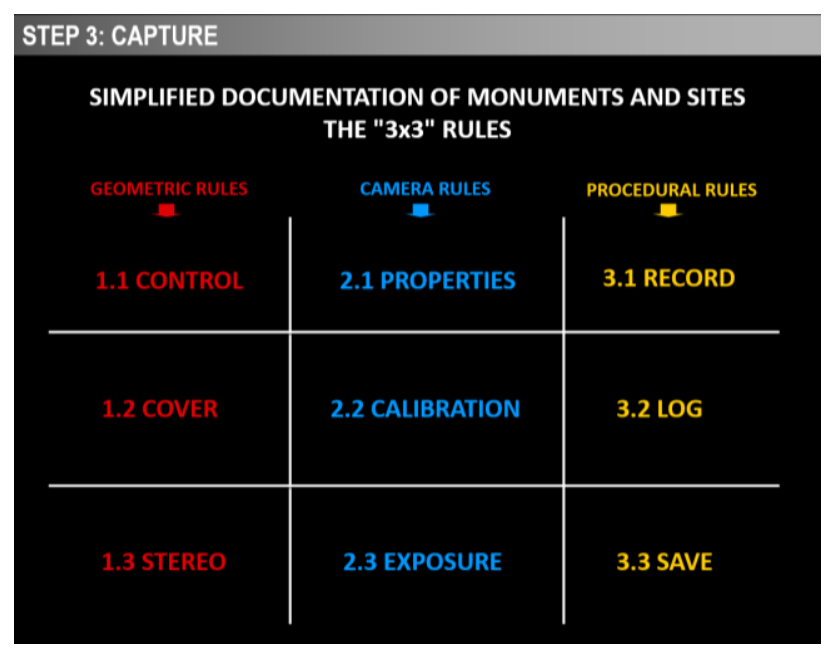

Figure 7. Simplified CIPA $3 \times 3$ rules (authors, 2012)

But in a crisis situation this is better than nothing, so the strategy is to empower the improvised recorders with the minimum knowledge in a minimum amount of time to provide the most and the best of what is possible and what they observe on-site. This might be the only primary data that will be collected probably in a certain period of time before experts can join the action to recover and stabilize structures and historical elements.

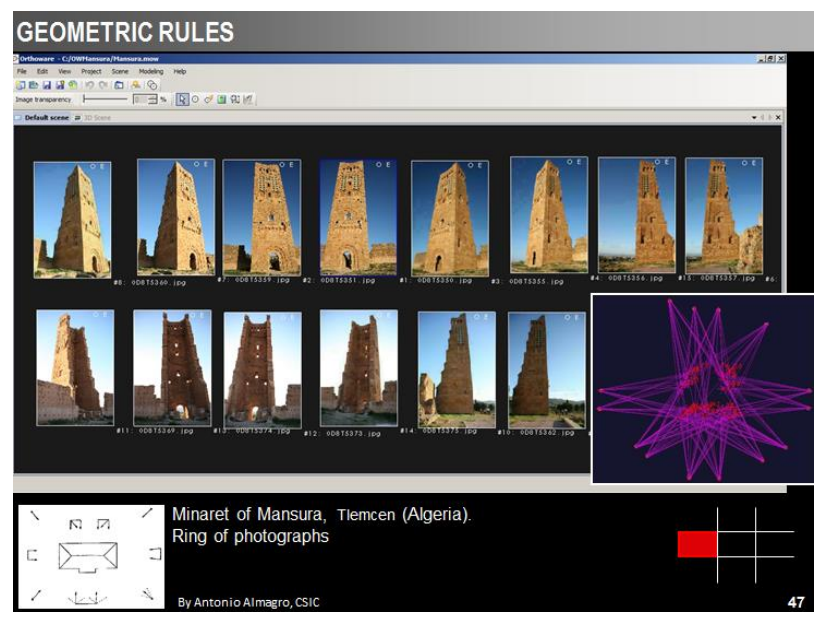

Figure 8. One of the geometric rules as part of the $3 \times 3$ rules: the ring of images around the subject. The Geometric rules were stressed as critical to ensure complete coverage of the monuments at risk. Participants practiced this and the other rules during the courses and they were shown how this ring of images, if correctly captured, could be further processed later as rectified images or even 3D models (Almagro, 2001)
Therefore there must be a compromise between what is considered the high standards possible in a non-conflict situation and those necessary during or immediately after a conflict. In this situation the recording process needs to maximize the amount of information that can be captured with a possibility of increasing in any possible way the quality of this data. The way to do it, so far, has been mainly through providing basic knowledge on photography and some of the geometric and camera rules tackled in the adapted $3 \times 3$ rules. Especially on how to cover systematically and in a consistent way the object, building or site, guaranteeing sufficient overlap and complementing a circular ring with oblique and straight up images of the item under study (Fig. 8).

\section{CONCLUSIONS}

ICCROM's initiative to launch in partnership with other institutions the courses on First Aid to Cultural Heritage in Times on Crisis is the key to tackle such dramatic situations. These courses aim to strengthen national and local capacities for protecting Cultural Heritage during complex emergencies, emphasizing cooperation and coordination with other mainstream emergency response actors, and identifying areas of joint programming between culture and humanitarian sectors.

The aim is to ensure that the affected communities participate in their own cultural protection and recovery, which in turn can become a driver for peace and comprehensive development after the crisis. An important aspect of this training in order to protect Cultural Heritage is information collection, analysis and monitoring of sites and museum collections. Data must be collected, processed and analyzed before any action can be taken, and how this process should be carried out is the primary goal of the specific module on rapid documentation developed according to the specific needs of such emergency situations.

On one hand, this documentation process must be fast, easy and inexpensive so that a larger number of individuals can join the action on the ground, coordinated and constantly in collaboration with other emergency forces. On the other hand, it is of utmost importance to collect documentation that can be analysed and provide additional information later. It is a delicate balance. In addition this process seeks to leverage the information already existing from secondary sources and how much information can be extracted from it, as this will constitute the base for any strategic documentation process on site. Leverage of the tools already available as well as the skills of the team that will work together was a critical point stressed. Time and planning were also emphasized as being necessary in the preliminary stages of documentation efforts. Last but not least, efforts must be joined through social media, such as crowdsource mapping initiatives, which can provide extremely useful information.

In a crisis time plays a fundamental role in our mission to preserve Cultural Heritage, and in most cases time runs against us. Cultural Heritage after a conflict will be damaged or destroyed at a faster rate than it can be accessed and recorded. Therefore any possible and imaginable way to preserve the memory of these places is essential and must be considered. It is our responsibility to provide assistance and improve the skills of all those who deal in their everyday activity with such difficult circumstances. 


\section{ACKNOWLEDGEMENTS}

The authors of this paper would like to first acknowledge and thank all those dedicated to saving Cultural Heritage after conflicts. Their work is essential for preserving the memories, symbols, artefacts, structures and more cultural elements of so many communities around the world. Often their hard work and efforts go unacknowledged in the face of humanitarian relief. The authors would also like to thank all the many instructors over the years at the Courses on First Aid for Cultural Heritage in Times of Crisis for dedicating their time and knowledge to improve safeguarding of Cultural Heritage after a crisis, as well as the International Committee on Risk Preparedness of ICOMOS. Finally, special thanks must be given to the managers, sponsors and supporters of the courses: ICCROM, the Prince Claus Fund, UNESCO, The Netherlands National Commission for UNESCO, Smithsonian Institution and others that with their support and effort make this important course become a reality.

\section{REFERENCES}

Almagro A., 2001. Simple methods of photogrammetry: easy and fast, in CIPA Heritage documentation, XVIII International Symposium of CIPA, Potsdam

Blake, B., Georgopoulos, A., Lerma, J. L., 2013 (last update). The CIPA $3 \times 3$ rules.

http://cipa.icomos.org/fileadmin/template/pdf/3x3-

23_10_2013.pdf

Council of Europe, 2011. The role of culture and cultural heritage in conflict prevention, transformation, resolution and post-conflict action: the Council of Europe approach https://www.coe.int/t/dg4/cultureheritage/News/CultureReconci liation_en.pdf

D'Ayala, Smars, 2003. Minimum requirements for metric use of non-metric photographic documentation, University of Bath

Eppich, R., Almagro Vidal, A., 2013. Challenges, strategies and techniques for international training in technology for cultural heritage conservation in Proceedings of the XXIV International Scientific Symposium of CIPA (Strasbourg (France), 2-6 Septembre 2013). ISPRS Annals of the Photogrammetry, Remote Sensing and Spatial Information Sciences, Volume II5/W1, 2013. pp. 109-114.

ICCROM, 2012. Protecting Cultural Heritage in Times of Conflict. Contributions from the participants of the International Course on First Aid to Cultural Heritage in Times of Conflict. Edited by Simon Lambert and Cynthia Rockwell.

ICOMOS, 1996. Principles for the recording of monuments, groups of buildings and sites. 11th ICOMOS General Assembly in Sofia, October 1996.

Kila, J. D., Zeidler, J. A., 2013. Cultural Heritage in the Crosshairs. Protecting Cultural Property during Conflict

Letellier, R., 2007. Recording, Documentation, and Information Management for the Conservation of Heritage Places: Guiding Principles, The Getty Conservation Institute, Los Angeles.
Stanley-Price, N., 2007. Cultural Heritage in Postwar Recovery.

Tandon, A., 2011. Cultural Emergency in Conflict and Disaster.

Tandon, A. 2015 First Aid to Cultural Heritage in Times of Crisis Framework Document, ICCROM, Smithsonian Institution, UNESCO Netherlands National Commission, Cultural Cannot Wait.

Van der Plas, E., Mendez, C. (Eds.), 2006. Culture is a Basic Need, Prince Claus Fund Journal \# 14.

http://www.princeclausfund.org/files/docs/PCFJournal14.pdf

Waldhäusl P., Ogleby C., 1994. 3x3 Rules for Simple Photogrammetric Documentation of Architecture, In: Frier, J.G. (ed.), Close Range Techniques and Machine Vision, Proceedings of the Symposium of Commission $V$ of ISPRS Melbourne, Australia. 